\title{
The role of oligohydramnios and fetal growth restriction in adverse pregnancy outcomes in preeclamptic patients
}

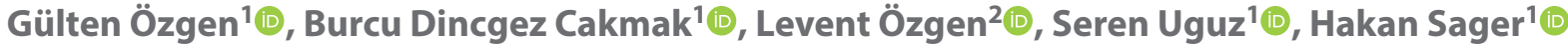 \\ ${ }^{1}$ Bursa Yüksek ihtisas Training and Research Hospital Department of Gynecology and Obstetrics, Bursa, Turkey \\ ${ }^{2}$ Bursa CityHospital, T.c. Sağlık Bakanlığı Bursa Şehir Hastanesi, Bursa, Turkey
}

\begin{abstract}
Objectives: We aimed to compare perinatal outcomes of oligohydramnios or fetal growth restriction with normal amniotic fluid index and fetal growth in preeclampsia and to compare the outcomes of only oligohydramnios, only fetal growth restriction and oligohydramnios with fetal growth restriction preeclamptic groups.

Material and methods: A total of 743 preeclamptic patients were evaluated between June 2016 and 2020. Patients were divided into two groups: preeclampsia with oligohydramnios or fetal growth restriction $(n=237)$ and preeclampsia with normal amniotic fluid index and fetal growth $(n=506)$. Then, the first group was divided subgroups as only oligohydramnios $(n=55)$, only fetal growth restriction $(n=125)$ and oligohydramnios with fetal growth restriction $(n=57)$. Demographic characteristics and perinatal outcomes were recorded.

Results: Gestational age at delivery $(p<0.001)$, birth weight $(p<0.001)$, Apgar scores $(p<0.001)$ and eclampsia $(p<0.001)$ were lower whereas impaired doppler findings $(p<0.001)$, cesarean rates $(p<0.001)$, preterm delivery $(p<0.001)$, abruptio placenta $(p<0.001)$, acute fetal distress $(p<0.001)$, RDS $(p<0.001)$, NICU requirement $(p<0.001)$ and neonatal death $(p<0.001)$ were higher in oligohydramnios or fetal growth restriction preeclamptic group. In subgroup analysis, there were differences between three groups according to the gestational age $(p<0.001)$, cesarean rates $(p=0.002)$, preterm delivery $(p<0.001)$, intensive care unit requirement $(p=0.039)$, birth weight $(p<0.001)$, Apgar scores $(p<0.001)$, RDS $(p<0.001)$ and NICU requirement $(p<0.001)$. In pairwise comparison, there was significant difference between only oligohydramnios and only fetal growth restriction group and between only oligohydramnios and oligohydramnios with fetal growth restriction group according to birth weight, Apgar scores, preterm delivery and cesarean rates, presence of RDS, maternal and neonatal intensive care unit requirement. No significant difference was detected between only fetal growth restriction group and oligohydramnios with fetal growth restriction group in terms of all parameters.

Conclusions: We suggest that patients with only oligohydramniosis have more favorable pregnancy outcomes than pregnants with only fetal growth restriction and coexistence of two conditions in preeclamptic patients. We claim that it could be appropriate to recommend close monitorization in preeclamptic patients with only fetal growth restriction and oligohydramniosis and fetal growth restriction.
\end{abstract}

Key words: adverse pregnancy outcome; fetal growth restriction; oligohydramnios; preeclampsia

Ginekologia Polska 2022; 93, 3: 235-241

\section{INTRODUCTION}

Preeclampsia, defined as the presence of hypertension in after late second trimester accompanied by proteinuria, maternal organ dysfunction or uteroplacental dysfunction, complicates approximately $2.5-8 \%$ of the pregnancies [1, 2]. Preeclampsia has catastrophic consequences such as fetal and maternal death. Moreover, it is tightly related to adverse perinatal outcomes including increased cesarean section rate, low Apgar scores, prematurity, placental abruption, HELLP (hemolysis, elevated liver enzymes, low platelets) syndrome, eclampsia, disseminated intravascular coagulation and increased maternal/fetal intensive care unit requirement [3].

Fetal growth restriction can be defined as an inadequate fetal growth compared to the expected growth potential based on the estimated fetal weight and/or abdominal

\footnotetext{
Corresponding author:

Burcu Dincgez Cakmak

Bursa Yüksek Ihtisas Training and Research Hospital Department of Gynecology and Obstetrics, Bursa, Turkey

e-mail:burcumavis@gmail.com
} 
circumference after adjusted for gestational age, race and gender [4]. It is related to perinatal mortality and morbidity. Furthermore, it contributes to chronic diseases such as hypertensive disorders [5]. In previous studies, preeclamptic patients have increased odds of fetal growth restriction and fetal growth restriction is claimed to be the indicator of severity of preeclampsia [6].

Amniotic fluid is a liquid surrounding the fetus and providing optimal environment for fetal development of fetal respiratory, gastrointestinal, musculoskeletal and urinary system [7]. Normal amniotic fluid index varies between 5-24 centimeters and oligohydramnios is defined as an amniotic fluid index below five centimeters [8]. Oligohydramnios can lead to fetal growth restriction, pulmonary hypoplasia, cord compression, low Apgar scores, fetal mortality and increased cesarean section rates [9-11]. Oligohydramnios could be found as a concomitant condition in $10-30 \%$ of preeclamptic patients with or without fetal growth restriction [12].

Placental insufficiency is claimed to have a key role in preeclampsia. Similarly, fetal growth restriction could result from abnormal placentation leads to inadequate uteroplacental blood flow [13]. Another condition which arises from placental insufficiency is oligohydramnios. Therefore, preeclampsia, fetal growth restriction and oligohydramnios are the conditions rising from the same etiopathogenesis named as placental insufficiency [14]. Thus, the clinical conditions are in relationship with each other and affects adverse perinatal outcomes. However, there are data in the literature evaluating the effect of oligohydramnios and fetal growth restriction together in preeclampsia, there is no evidence about the separate roles of oligohydramnios and fetal growth restriction in adverse pregnancy outcomes in preeclampsia.

To the best of our knowledge, it is the first study searching the perinatal outcomes of preeclamptic patients by dividing the parturients with only oligohydramnios, only fetal growth restriction and oligohydramnios with fetal growth restriction. In this study, we aimed to compare the perinatal outcomes of oligohydramnios or fetal growth restriction preeclamptic group with normal amniotic fluid index and fetal growth preeclamptic group and to compare the outcomes of only oligohydramnios, only fetal growth restriction and oligohydramnios with fetal growth restriction preeclamptic groups.

\section{MATERIAL AND METHODS}

This retrospective study was performed at the obstetrics and gynecology department of a university affiliated research and training hospital between June 2016 and June 2020. At admission, informed consent for being a participant of a study is routinely taken from all participants. The study was approved by the local Ethics Committee of University of Health Sciences, Bursa Yuksek Ihtisas Research and Training Hospital with a decision number of 2011-KAEK25 2020/06-13.

\section{Study population}

The study included 743 preeclamptic patients who admitted to our clinic for regular antenatal visits and gave a birth in our hospital between June 2016 and June 2020. Initially, preeclamptic patients were divided into two groups as: preeclampsia with oligohydramnios or fetal growth restriction $(n=237)$ and preeclampsia with normal amniotic fluid index and fetal growth $(n=506)$. After then, preeclampsia with oligohydramnios or fetal growth restriction group were divided into three subgroups as: only oligohydramnios $(n=55)$, only fetal growth restriction $(n=125)$ and oligohydramnios with fetal growth restriction $(n=57)$ group.

Demographic characteristics of the patients, gestational age at delivery, Doppler ultrasonography findings, delivery mode, birth weight, perinatal complications such as placental abruption, acute fetal distress, respiratory distress syndrome (RDS), HELLP syndrome, eclampsia, neonatal death, APGAR scores of neonates and maternal/fetal intensive care unit requirement were obtained from hospital medical records.

Exclusion criteria of the study were as follows: having unregular antenatal visit, uterine malformations, endocrine disorders such as diabetes mellitus and thyroid disorders, hematologic disorders leading thrombocytopenia, intrauterine infectious or inflammatory conditions, history of cardiac diseases, multiple pregnancy, congenital fetal anomalies, post term pregnancy, premature rupture of membranes, any hypertensive disorders except preeclampsia, pregestational diabetes mellitus, kidney or liver dysfunction leading to increased creatinine and transaminase levels, maternal drug use including angiotensin converting enzyme inhibitor or nonsteroid anti-inflammatory drugs, smoking and tobacco use.

Patients were followed with Umbilical artery Doppler velocimetry, nonstress tests and biophysical profiles after the diagnosis of fetal growth restriction. To improve preterm neonatal outcomes antenatal corticosteroids were applied before $336 / 7$ weeks and neuroprotective magnesium sulfate was administered in cases which were delivered before $32^{\text {nd }}$ gestational weeks. Additionally, we ordered antenatal corticosteroids for cases between 34-37 weeks of gestation who are at risk of preterm delivery within a week. No supplemental nutritional or dietary intake were ordered for these cases. Delivery mode was decided according to the obstetric indications and optimum delivery time was decided due to the gestational week and the cause of fetal growth restriction. 


\section{Statistical analysis}

Shapiro Wilk test was used to determine the normality of distribution. Mann Whitney $U$ test was performed to compare perinatal outcomes of oligohydramnios or fetal growth restriction preeclamptic group with normal amniotic fluid index and fetal growth preeclamptic group for continuous variables while chi-square test was used to compare categorical variables between two groups. Variables were expressed as median (minimum-maximum) for continuous variables and percentages for categorical variables. Kruskal Wallis test was carried out to compare patients with only oligohydramnios, only fetal growth restriction and oligohydramnios with fetal growth restriction preeclamptic groups. Furthermore, Mann Whitney U test was used for pairwise comparison. Categorical variables were compared with Chi-Square and Fisher's exact test. The level of significance was set at $a=0.05$. Statistical analysis of the study was performed by using SPSS Version 21.0. (IBM Corp. Released 2012. IBM SPSS Statistics for Windows, Armonk, NY: IBM Corp.) software.

\section{RESULTS}

Maternal demographic features and maternal outcomes of the study group were presented in Table 1. There was no statistically significant difference between oligohydramnios or fetal growth restriction preeclamptic group and preeclampsia with normal amniotic fluid index and fetal growth groups in terms of age, parity, HELLP syndrome and adult intensive care unit requirement. Oligohydramnios or fetal growth restriction preeclamptic group had statistically higher rates of impaired Doppler findings as compared to normal amniotic fluid index and fetal growth preeclamptic group ( $p<0.001$ ). According to maternal outcomes, gestational age at delivery and presence of eclampsia was significantly lower $(p<0.001)$ whereas cesarean section rates, the frequency of preterm delivery $(p<0.001)$, abruptio placenta $(p<0.001)$ and acute fetal distress $(p<0.001)$ were higher in oligohydramnios or fetal growth restriction preeclamptic group.

Neonatal outcomes of the study group were shown in Table 2. There was statistically significant difference with

Table1. Maternal features and outcomes of the study group

\begin{tabular}{|c|c|c|c|}
\hline & $\begin{array}{l}\text { Reduced amniotic volume or fetalgrowth } \\
\qquad(n=237)\end{array}$ & $\begin{array}{l}\text { Normal amniotic fluid and fetal growth } \\
\qquad(n=506)\end{array}$ & p value \\
\hline Age [years] & $26(17-41)$ & $26(16-41)$ & $0.081^{\mathrm{a}}$ \\
\hline Parity (n) & $2(0-7)$ & $2(0-8)$ & $0.246^{\mathrm{a}}$ \\
\hline Impaired Doppler findings (n, \%) & $20(8.4 \%)$ & $11(2.2 \%)$ & $<0.001^{b}$ \\
\hline Gestational age at delivery (week) & $34(24-39)$ & $37(27-41)$ & $<0.001^{\mathrm{a}}$ \\
\hline Cesarean section $(n, \%)$ & $129(54.4 \%)$ & $190(37.5 \%)$ & $<0.001^{b}$ \\
\hline Preterm delivery ( $n, \%)$ & $185(78.1 \%)$ & $214(42.3 \%)$ & $<0.001^{b}$ \\
\hline Abruptio placenta $(n, \%)$ & $12(5.1 \%)$ & $17(3.4 \%)$ & $<0.001^{b}$ \\
\hline Acute fetal distress (n, \%) & $73(30.8 \%)$ & $97(19.2 \%)$ & $<0.001^{b}$ \\
\hline HELLP syndrome $(n, \%)$ & $14(5.9 \%)$ & $17(3.4 \%)$ & $0.106^{b}$ \\
\hline Eclampsia (n, \%) & $6(2.5 \%)$ & $20(4 \%)$ & $<0.001^{b}$ \\
\hline Intensive care unit requirement $(\mathrm{n}, \%)$ & $27(11.4 \%)$ & $41(8.1 \%)$ & $0.147^{b}$ \\
\hline
\end{tabular}

Data areexpressed as median (minimum-maximum) or $\mathrm{n}(\%)$; ${ }^{a}$ Mann-Whitney $\mathrm{U}$ test; ${ }^{\mathrm{b}} \mathrm{Chi}$-Square test; $\mathrm{HELLP}$ — hemolysis, elevated liver enzymes, low platelets

Table 2. Neonatal outcomes of the study group

\begin{tabular}{|c|c|c|c|}
\hline & $\begin{array}{l}\text { Oligohydramnios or fetal growth } \\
\qquad(n=237)\end{array}$ & $\begin{array}{l}\text { Normal amniotic fluid and fetal growth } \\
\qquad(\mathrm{n}=506)\end{array}$ & p value \\
\hline Birthweight [week] & $1680(405-4780)$ & $2910(560-4720)$ & $<0.001^{\mathrm{a}}$ \\
\hline Apgar $1^{\text {st }}[$ minute $]$ & $6(0-9)$ & $8(0-9)$ & $<0.001^{\mathrm{a}}$ \\
\hline Apgar $5^{\text {th }}$ [minute] & $8(0-10)$ & $9(0-10)$ & $<0.001^{\mathrm{a}}$ \\
\hline $\operatorname{RDS}(n, \%)$ & $120(50.6 \%)$ & $72(14.2 \%)$ & $<0.001^{b}$ \\
\hline $\operatorname{NICU}(n, \%)$ & $157(66.2 \%)$ & $100(19.8 \%)$ & $<0.001^{b}$ \\
\hline Neonatal death $(n, \%)$ & $18(7.6 \%)$ & $12(2.4 \%)$ & $<0.001^{b}$ \\
\hline
\end{tabular}

Data are expressed as median (minimum-maximum) or $n$ (\%); ${ }^{a}$ Mann-Whitney U test; ${ }^{b}$ Chi-Square test; $\mathrm{RDS}$ — respiratory distress syndrome; NICU — Neonatal Intensive Care Unit 
regard to all neonatal outcomes between two groups. While birthweight ( $p<0.001)$, Apgar scores of first minutes $(p<0.001)$, Apgar scores of fifth minutes $(p<0.001)$ were significantly lower in oligohydramnios or fetal growth restriction preeclamptic group, the rates of RDS $(p<0.001)$, NICU requirement $(p<0.001)$ and neonatal death $(p<0.001)$ were higher than normal amniotic fluid index and fetal growth preeclampsia group.

Maternal demographic features and maternal outcomes of only oligohydramnios, only fetal growth restriction and oligohydramnios with fetal growth restriction groups were demonstrated in Table 3 . In subgroup analysis, no significant difference was found between subgroups in terms of age, parity, the frequency of impaired doppler findings, abruptio placenta, acute fetal distress, HELLP syndrome and eclampsia. There was difference between three groups according to the gestational age at delivery $(p<0.001)$, cesarean section rates $(p=0.002)$, preterm delivery $(p<0.001)$ and intensive care unit requirement $(p=0.039)$.

Neonatal outcomes of the subgroups were shown in Table 4. There was statistically significant difference between three groups according to birth weight $(p<0.001)$, Apgar scores of first minutes $(p<0.001)$, Apgar scores of fifth minutes $(p<0.001), \operatorname{RDS}(p<0.001)$ and NICU requirement $(p<0.001)$.

Pairwise comparison of groups were shown in Table 5. There was statistically significant difference between only oligohydramnios and only fetal growth restriction group and between only oligohydramnios and oligohydramnios with fetal growth restriction group with regard to birth weight, Apgar scores of first and fifth minutes, preterm delivery and cesarean section rates, presence of RDS, maternal and neonatal intensive care unit requirement. No significant dif- ference was detected between only fetal growth restriction group and oligohydramnios with fetal growth restriction group in terms of all parameters.

\section{DISCUSSION}

The main findings of the study were as follows: 1. Preeclamptic patients with oligohydramnios or fetal growth restriction had higher rates of impaired Doppler findings, lower gestational age at delivery, birthweight, Apgar scores, higher cesarean section rates, frequency of preterm delivery, abruptio placenta, acute fetal distress, RDS, NICU requirementand neonatal death as compared to normal amniotic fluid index and fetal growth preeclamptic group; 2. In subgroup analysis, there was significant difference between only oligohydramnios and only fetal growth restriction group and between only oligohydramnios and oligohydramnios with fetal growth restriction group with regard to birth weight, Apgar scores of first and fifth minutes, preterm delivery and cesarean section rates, presence of RDS, maternal and neonatal intensive care unit requirement. No significant difference was detected between only fetal growth restriction group and oligohydramnios with fetal growth restriction group in terms of all parameters.

Preeclampsia, one of the most common cause of perinatal mortality and morbidity, complicates nearly $4-5 \%$ of pregnancies among worldwide [15]. Although many etiologic factors were claimed to play a role in the etiopathogenesis of preeclampsia, the main underlying mechanism remains unclear. Abnormal placentation, oxidative stress, immune mechanisms, endothelial dysfunction and imbalance in angiogenesis are some of the mechanisms of preeclampsia. Whereas researchers hypothesized that impaired

Table 3. Maternal features and outcomes of the study subgroups

\begin{tabular}{|c|c|c|c|c|}
\hline & $\begin{array}{l}\text { Only oligohydramnios } \\
\qquad(n=55)\end{array}$ & $\begin{array}{l}\text { Only fetal growth restriction } \\
\qquad(n=125)\end{array}$ & $\begin{array}{l}\text { Oligohydramnios and fetal } \\
\text { restriction }(n=57)\end{array}$ & $p$ value \\
\hline Age [years] & $26(17-41)$ & $26(17-41)$ & $26(17-41)$ & $0.556^{b}$ \\
\hline Parity (n) & $2(0-5)$ & $2(0-7)$ & $2(0-5)$ & $0.570^{b}$ \\
\hline $\begin{array}{l}\text { Impaired Doppler } \\
\text { findings }(n, \%)\end{array}$ & $6(10.9 \%)$ & $9(7.2 \%)$ & $5(8.8 \%)$ & $0.676^{C}$ \\
\hline $\begin{array}{l}\text { Gestational age at } \\
\text { delivery [minute] }\end{array}$ & $36(25-39)$ & $33(24-38)$ & $33(25-38)$ & $<0.001^{b}$ \\
\hline Cesarean section $(n, \%)$ & $19(34.5 \%)$ & $73(58.4 \%)$ & 37 (64.9\%) & $0.002^{\mathrm{a}}$ \\
\hline Preterm delivery $(\mathrm{n}, \%)$ & $32(58.2 \%)$ & $104(83.2 \%)$ & $49(86 \%)$ & $<0.00^{\mathrm{a}}$ \\
\hline Abruptio placenta $(n, \%)$ & $0(0 \%)$ & $7(5.6 \%)$ & $5(8.8 \%)$ & $0.070^{C}$ \\
\hline Acute fetal distress $(n, \%)$ & $12(21.8 \%)$ & $46(36.8 \%)$ & $15(26.3 \%)$ & $0.094^{\mathrm{a}}$ \\
\hline HELLP syndrome (n, \%) & $1(1.8 \%)$ & $8(6.4 \%)$ & $5(8.8 \%)$ & $0.290^{C}$ \\
\hline Eclampsia (n, \%) & $1(1.8 \%)$ & $3(2.4 \%)$ & $2(3.5 \%)$ & $0.868^{C}$ \\
\hline $\begin{array}{l}\text { Intensive careunit } \\
\text { Requirement }(\mathrm{n}, \%)\end{array}$ & $1(1.8 \%)$ & $18(14.4 \%)$ & $8(14 \%)$ & $0.039^{a}$ \\
\hline
\end{tabular}

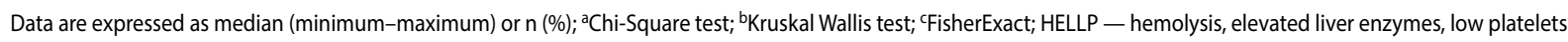




\begin{tabular}{|c|c|c|c|c|}
\hline & $\begin{array}{l}\text { Only oligohydramnios } \\
\qquad(n=55)\end{array}$ & $\begin{array}{l}\text { Only fetal growth restriction } \\
\qquad(\mathrm{n}=125)\end{array}$ & $\begin{array}{l}\text { Oligohydramnios and fetal } \\
\text { growth restriction }(n=57)\end{array}$ & $p$ value \\
\hline Birth weight [week] & $2460(610-4780)$ & $1520(405-3360)$ & $1390(525-2350)$ & $<0.001^{\mathrm{a}}$ \\
\hline Apgar $1^{\text {st }}$ [minute] & $8(3-9)$ & $6(0-9)$ & $6(0-8)$ & $<0.001^{\mathrm{a}}$ \\
\hline Apgar $5^{\text {th }}$ [minute] & $9(4-10)$ & $7(0-10)$ & $7(0-9)$ & $<0.001^{\mathrm{a}}$ \\
\hline $\operatorname{RDS}(n, \%)$ & $16(29.1 \%)$ & $69(55.2 \%)$ & $35(61.4 \%)$ & $0.001^{b}$ \\
\hline $\operatorname{NICU}(n, \%)$ & $25(45.5 \%)$ & 89 (71.2\%) & $43(75.4 \%)$ & $0.001^{\mathrm{b}}$ \\
\hline Neonatal death n, \%) & $1(1.8 \%)$ & $12(9.6 \%)$ & $5(8.8 \%)$ & $0.176^{\mathrm{b}}$ \\
\hline
\end{tabular}

Data are expressed as median (minimum-maximum) or n (\%); ${ }^{a}$ Mann-Whitney U test; ${ }^{b}$ Chi-Squaretest; RDS — respiratory distress syndrome; NICU — Neonatal Intensive Care Unit

\begin{tabular}{|l|c|c|c|}
\hline \multicolumn{4}{|c|}{ Table 5. Pairwise comparison of subgroups } \\
\hline & $\mathbf{p = 1 - 2}$ & $\mathbf{p = 1 - 3}$ & $\mathbf{p = 2 - 3}$ \\
\hline Birth weight [week] & $<0.001$ & 0.001 & 0.288 \\
\hline Apgar 1 ${ }^{\text {st }}$ [minute] & $<0.001$ & $<0.001$ & 0.148 \\
\hline Apgar 5 $^{\text {th }}$ [minute] & $<0.001$ & $<0.001$ & 0.161 \\
\hline Preterm delivery (n, \%) & $<0.001$ & 0.001 & 0.286 \\
\hline Cesarean section (n, \%) & 0.003 & 0.001 & 0.405 \\
\hline RDS (n, \%) & 0.001 & 0.001 & 0.433 \\
\hline NICU (n, \%) & 0.001 & 0.001 & 0.552 \\
\hline Intensive care unit requirement & 0.011 & 0.032 & 0.948 \\
\hline$(n, \%)$ & & & \\
\hline
\end{tabular}

RDS - respiratory distress syndrome; NICU — Neonatal Intensive Care Unit

placentation has the key role in preeclampsia in 1960, the disease is accepted to occur in terms of both abnormal placentation followed by maternal vascular dysfunction in recent times [16].

In the literature, it has been shown that the number placental infarcts suggesting placental hypoperfusion and ischaemia are increased in preeclamptic women [17]. In a study evaluating placental bed samples, the authors demonstrated increased thrombotic occlusion in vessels and lipophage infiltration in preeclampsia as compared to other hypertensive conditions [18]. In another study, the spiral arteries in placental bed samples were found to be narrowed in preeclampsia than normal pregnancies [19]. Moreover, the severity of preeclampsia was shown to be correlated with the atherosis and sclerosis of arterial structures, fibrin deposition and infarction leading to placental insufficiency [20].

Another remarkable issue about placental insufficiency is the relationship between abnormal placentation and fetal growth restriction accompanying preeclampsia. Recent study has shown more common major defects in spiral arteries in preeclamptic women when it is complicated with fetal growth restriction [21].

Fetal growth restriction is defined as estimated fetal weight or abdominal circumference below $10^{\text {th }}$ percentile and/or abnormal Doppler waveforms by current guidelines. Fetal growth restriction could occur due to the maternal, fetal or placental factors. Likewise, to preeclampsia, reduced utero placental blood flow named as placental insufficiency is the main contributor of fetal growth restriction. Furthermore, it is clearly known that impaired secretion of proangiogenic factors, enhanced secretion of soluble fms-like tyrosine kinase-1, placental infarction and decidual vasculopathy are the etiologic mechanisms both in preeclampsia and fetal growth restriction [22].

Oligohydramnios is another condition that is related with placental insufficiency. In a study of Rabinovich, the possible mechanism of oligohydramnios in preeclampsia is reported to be placental insufficiency [13]. Placental insufficiency leads to shunt the blood flow from nonessential organs such as kidneys to the essential ones such as the brain. This condition causes reduced renal flow and urine output which consequently results in oligohydramnios [23].

The aforementioned above preeclampsia, fetal growth restriction and oligohydramnios are tightly related entities with placental insufficiency. There are many studies in the literature searching the placental pathologies or pregnancy outcomes of those conditions separately or concomitantly. In contrast there is only a few data in the literature evaluating the effect of oligohydramnios and fetal growth restriction together in preeclampsia.

Balogun et al. [24] claimed that preterm preeclamptic parturients with fetal growth restriction have higher composite maternal and neonatal morbidity risk than appropriate for gestational age cases. Similarly, Haddad et al. [25] showed that severe fetal growth restriction is associated with increased fetal death risk while maternal complications were not different in preterm severe preeclampsia cases.

In the study of Rabinovich et al. [13] 81 preterm preeclamptic patients with oligohydramnios and 81 preterm preeclamptic patients with normal amniotic fluid were compared. They found that birth weights were lower, fetal distress during labor was more frequent, neonatal anemia was more common and hospitalization in NICU was longer 
in oligohydramnios group. In addition to this, they reported that oligohydramnios is an independent risk factor for early neonatal morbidity in preterm preeclamptic patients. In contrast, in a study of Barrilleaux et al. [26] searching preterm preeclamptic patients with HELLP syndrome, they reported that amniotic fluid index is a poor predictor for neonatal outcome. Rabie et al. [27] claimed that oligohydramnios was related to lower birth weight in preterm preeclampsia while no significant association was found for cesarean section rates and NICU admission.

There are conflicting results for the relationship between oligohydramnios and adverse perinatal outcomes in pregnancies with fetal growth restriction [28]. However, no association was reported in some studies, Sasahara et al. [29], showed that reduced amniotic fluid is a predictor for cerebral palsy and mortality in preterm fetal growth restriction cases. Spinollo et al. [30] showed that reduced amniotic fluid index is correlated with the features of histopathological signs of placental insufficiency in fetal growth restriction. In another study evaluating the role of oligohydramnios in fetal growth restriction pregnancies, oligohydramnios was found to be associated with fetal hypoxia, fetal distress and abnormal Doppler findings [31-33].

In this study, we searched for the perinatal outcomes of preeclamptic patients by dividing the parturients with only oligohydramnios, only fetal growth restriction and oligohydramnios with fetal growth restriction for the first time. We compared the perinatal outcomes of oligohydramnios or fetal growth restriction preeclamptic group with normal amniotic fluid index and fetal growth preeclamptic group and compared the outcomes of only oligohydramnios, only fetal growth restriction and oligohydramnios with fetal growth restriction preeclamptic groups. We showed that oligohydramnios or fetal growth restriction preeclamptic group has worsened perinatal outcomes than normal amniotic fluid and fetal growth preeclamptic patients. Moreover, we found that preeclamptic paturients with only oligohydramnios have favorable pregnancy outcomes as compared to only fetal growth restriction or coexistence of these conditions. It is known that preeclampsia can affect amniotic fluid volume by changing transplacental and transmembrane water dynamics while redistribution of blood flow to essential organs and placental vascular resistance are more prominent mechanism in fetal growth restriction. Thus, it may not be amazing that preeclamptic patients with fetal growth restriction have worse pregnancy outcomes because of vascular injuries and altered blood flow in addition to the changes in water dynamics.

\section{CONCLUSIONS}

Oligohydramniosis and fetal growth restriction are entities arising from same etiopathogenesis. It is known that pregnancies with oligohydramniosis and fetal growth restriction have worsened outcomes. Here, we suggest that patients who have only Oligohydramniosis have more favorable pregnancy outcomes as compared to parturients with only fetal growth restriction and coexistence of two conditions in preeclamptic patients. So, we claim that it could be appropriate to recommend close monitorization in preeclamptic patients with only fetal growth restriction and oligohydramniosis and fetal growth restriction.

\section{Financial disclosure}

The authors receive no financial support for the study conduct.

\section{Ethical disclosure}

A written informed consent was obtained from each participant. The study protocol was approved by the Ethics Committee of Bursa Yüksek İhtisas Training and Research Hospital. The study was conducted in accordance with the principles of the Declaration of Helsinki.

\section{Conflict of interest}

The authors declare no conflict of interest. The authors are solely responsible for the content and writing of the paper.

\section{REFERENCES}

1. World Health Organization,UNICEF, UNFPA and the World Bank. 2012. Trends in Maternal Mortality: 1990 to 2010. Geneva:World Health Organization. http//whqlibdoc.who.int/publications/2012/9789241503631_ eng.pdf. (2014 Dec 12).

2. ACOG Practice Bulletin No. 202 Summary: Gestational Hypertension and Preeclampsia. Obstet Gynecol. 2019; 133(1): 1, doi: 10.1097/AOG.0000000000003019, indexed in Pubmed: 30575668.

3. Delahaije DHJ, Smits LJM, van Kuijk SMJ, et al. Care-as-usual provided to formerly preeclamptic women in the Netherlands in the next pregnancy: health care consumption, costs and maternal and child outcome. Eur J Obstet Gynecol Reprod Biol. 2014; 179: 240-245, doi: 10.1016/j. ejogrb.2014.04.033, indexed in Pubmed: 24835859.

4. Kesavan K, Devaskar SU. Intrauterine Growth Restriction: Postnatal Monitoring and Outcomes. Pediatr Clin North Am. 2019; 66(2): 403-423, doi: 10.1016/j.pcl.2018.12.009, indexed in Pubmed: 30819345.

5. Rosenberg A.The IUGR newborn. Semin Perinatol. 2008; 32(3): 219-224, doi: 10.1053/j.semperi.2007.11.003, indexed in Pubmed: 18482625.

6. Srinivas SK, Edlow AG, Neff PM, et al. Rethinking IUGR in preeclampsia: dependent or independent of maternal hypertension? J Perinatol. 2009; 29(10): 680-684, doi: 10.1038/jp.2009.83, indexed in Pubmed: 19609308.

7. Weiner E, Feldstein O, Tamayev L, et al. Placental histopathological lesions in correlation with neonatal outcome in preeclampsia with and without severe features. Pregnancy Hypertens. 2018; 12: 6-10, doi: 10.1016/j. preghy.2018.02.001, indexed in Pubmed: 29674201.

8. Rathod S, Samal SK. Evaluation of maternal and perinatal outcomes of induction in borderline oligohydramnios at term. J Clin Diagn Res. 2017; 11(9): QC05-QC07, doi: 10.7860/JCDR/2017/26313.10612, indexed in Pubmed: 29207783.

9. Naveiro-Fuentes M, Puertas Prieto A, Ruíz RS, et al. Perinatal outcomes with isolated oligohydramnios at term pregnancy. J Perinat Med. 2016; 44(7): 793-798, doi: 10.1515/.jpm-2015-0198, indexed in Pubmed: 26506098

10. Phelan JP, Smith CV, Broussard P, et al. Amniotic fluid volume assessment with the four-quadrant technique at 36-42 weeks' gestation. J Reprod Med. 1987; 32(7): 540-542, indexed in Pubmed: 3305930. 
11. Manzanares S, Carrillo MP, González-Perán E, et al. Isolated oligohydramnios in term pregnancy as an indication for induction of labor. J Matern Fetal Neonatal Med. 2007; 20(3): 221-224, doi: 10.1080/14767050601127391, indexed in Pubmed: 17437223.

12. Aceituno Velasco L, Aguayo Maldonado J, Arribas Mir L, Caño Aguilar A, Corona Páez I, Martín López JE, et al. Embarazo Parto y puerperio. Proceso Asistencial Integrado. 3a Ed. Sevilla: Junta de Andalucía, Consejería de Salud, 2014. . http://www.juntadeandalucia.es/salud/sites/csalud/contenidos/Informacion_General/p_3_p_3_procesos_asistenciales_integrados/pai/embarazo_parto_puerperio_v3?perfil=org.

13. Rabinovich A, Holtzman K, Shoham-Vardi I, et al. Oligohydramnios is an independent risk factor for perinatal morbidity among women with pre-eclampsia who delivered preterm. J Matern Fetal Neonatal Med. 2019;32(11): 1776-1782, doi: 10.1080/14767058.2017.1417377, indexed in Pubmed: 29237307.

14. Norwitz ER, Norwitz ER. Defective implantation and placentation: laying the blueprint for pregnancy complications. Reprod Biomed Online. 2006; 13(4): 591-599, doi: 10.1016/s1472-6483(10)60649-9, indexed in Pubmed: 17007686

15. Ananth CV, Keyes KM, Wapner RJ. Pre-eclampsia rates in the United States, 1980-2010: age-period-cohort analysis. BMJ. 2013; 347: f6564, doi: 10.1136/bmj.f6564, indexed in Pubmed: 24201165.

16. Phipps EA, Thadhani $R$, Benzing $T$, et al. Pre-eclampsia: pathogenesis, novel diagnostics and therapies. Nat Rev Nephrol. 2019; 15(5): 275-289, doi: 10.1038/s41581-019-0119-6, indexed in Pubmed: 30792480.

17. Young J. The AEtiology of Eclampsia and albuminuria and their relation to accidental haemorrhage: (An anatomical and experimental investigation.). Proc R Soc Med. 1914; 7(Obstet Gynaecol Sect): 307-348, indexed in Pubmed: 19978036.

18. Brosens IA, Robertson WB, Dixon HG. The role of the spiral arteries in the pathogenesis of preeclampsia. Obstet Gynecol Annu. 1972; 1: 177-191, indexed in Pubmed: 4669123.

19. Zhou Y, Fisher SJ, Janatpour M, et al. Human cytotrophoblasts adopt a vascular phenotype as they differentiate. A strategy for successful endovascular invasion? J Clin Invest. 1997; 99(9): 2139-2151, doi: 10.1172/JCl1 19387, indexed in Pubmed: 9151786

20. Hecht JL, Zsengeller ZK, Spiel M, et al. Revisiting decidual vasculopathy. Placenta. 2016; 42: 37-43, doi: 10.1016/j.placenta.2016.04.006, indexed in Pubmed: 27238712.

21. Lyall F, Robson SC, Bulmer JN. Spiral artery remodeling and trophoblast invasion in preeclampsia and fetal growth restriction: relationship to clinical outcome. Hypertension. 2013; 62(6): 1046-1054, doi: 10.1161/HYPERTENSIONAHA.113.01892, indexed in Pubmed: 24060885.
22. Audette $M$, Kingdom J. Screening for fetal growth restriction and placental insufficiency. Seminars in Fetal and Neonatal Medicine. 2018; 23(2): 119-125, doi: 10.1016/j.siny.2017.11.004.

23. Schucker JL, Mercer BM, Audibert F, et al. Serial amniotic fluid index in severe preeclampsia: a poor predictor of adverse outcome. Am J Obstet Gynecol. 1996; 175(4 Pt 1): 1018-1023, doi: 10.1016/s00029378(96)80045-7, indexed in Pubmed: 8885768.

24. Balogun OA, Khanagura RK, Kregel HR, et al. Preterm preeclampsia with severe features: composite maternal and neonatal morbidities associated with fetal growth restriction. Am J Perinatol. 2018; 35(8): 785-790, doi: 10.1055/s-0037-1617456, indexed in Pubmed: 29298455.

25. Haddad B, Kayem G, Deis S, et al. Are perinatal and maternal outcomes different during expectant management of severe preeclampsia in the presence of intrauterine growth restriction? Am J Obstet Gynecol. 2007; 196(3): 237.e1-237.e5, doi: 10.1016/j.ajog.2006.10.905, indexed in Pubmed: 17346535.

26. Barrilleaux PS, Magann EF, Chauhan SP, et al. Amniotic fluid index as a predictor of adverse perinatal outcome in the HELLP syndrome. J Reprod Med. 2007; 52(4): 293-298, indexed in Pubmed: 17506369.

27. Rabie N, Magann E, Steelman S, et al. Oligohydramnios in complicated and obstetrics \&gynecology :Ultrasound . Obstet Gynecol. 2017; 49: 442-449.

28. Magann EF, Haas DM, Hill JB, et al. Oligohydramnios, small for gestational age and pregnancy outcomes: an analysis using precise measures. Gynecol Obstet Invest. 2011; 72(4): 239-244, doi: 10.1159/000324570, indexed in Pubmed: 22041790.

29. Sasahara J, Ishii K, Umehara N, et al. Significance of oligohydramnios in preterm small-for-gestational-age infants for outcome at 18 months of age. J Obstet Gynaecol Res. 2016; 42(11): 1451-1456, doi: 10.1111/jog.13074, indexed in Pubmed: 27352940.

30. Spinillo A, Cesari S, Bariselli S, et al. Placental lesions associated with oligohydramnios in fetal growth restricted (FGR) pregnancies. Placenta. 2015; 36(5): 538-544, doi: 10.1016/j.placenta.2015.02.007, indexed in Pubmed: 25735841.

31. Cosmi E, Ambrosini G, D'Antona D, et al. Doppler, cardiotocography, and biophysical profile changes in growth-restricted fetuses. Obstet Gynecol. 2005; 106(6): 1240-1245, doi: 10.1097/01.AOG.0000187540.37795.3a, indexed in Pubmed: 16319247.

32. Chauhan SP, Sanderson M, Hendrix NW, et al. Perinatal outcome and amniotic fluid index in the antepartum and intrapartum periods: A meta-analysis. Am J Obstet Gynecol. 1999; 181(6): 1473-1478, doi: 10.1016/s0002-9378(99)70393-5, indexed in Pubmed: 10601931.

33. Bastide A, Manning F, Harman C, et al. Ultrasound evaluation of amniotic fluid: outcome of pregnancies with severe oligohydramnios. Am J Obstet Gynecol. 1986; 154(4): 895-900, doi: 10.1016/0002-9378(86)90479-5, indexed in Pubmed: 3515948. 